\title{
Voice over Internet Protocol (VoIP) Technology as a Global Learning Tool: Information Systems Success and Control Belief Perspectives
}

\author{
Charlie C. Chen \& Sandra Vannoy \\ Appalachian State University, United States
}

\begin{abstract}
Voice over Internet Protocol- (VoIP) enabled online learning service providers struggling with high attrition rates and low customer loyalty issues despite VoIP's high degree of system fit for online global learning applications. Effective solutions to this prevalent problem rely on the understanding of system quality, information quality, and individual beliefs about the usefulness of this technology. This research aims to provide insights into increasing the loyalty of users to VolP-enabled global learning programs from the perspectives of information systems (IS) success and control belief. A theoretical model is proposed to integrate seven major constructs of IS success and planned behavior theory. We tested our model using the path analysis of data collected from an experiment where 66 undergraduate students from the USA and Taiwan worked in pairs using Skype to improve their English and intercultural communication skills. Data analysis results showed that information quality and perceived behavioral control are much more important than system quality in increasing satisfaction with the use of Skype. An increase in user satisfaction can lead to an improvement in intercultural communication competence and to increased user loyalty. Theoretical and practical implications are drawn from the findings to conclude this study.
\end{abstract}

Keywords: Information quality; VoIP; Global learning tool; Perceived behavioral control; User satisfaction; Individual performance

\section{Introduction}

The effective delivery of a course should carefully consider the potential impact of "transactional distance," determined by the dialogue between the learner and the instructor on learning effectiveness (Wedemeyer, 1981; Moore, 1983). Personalized instruction methods can increase the rate of dialogue and shorten the transactional distance (Saba and Shearer, 1994). As a result, the learning effectiveness can be improved compared to the traditional "instructor control" delivery method.

VoIP (Voice over Internet Protocol) technology was originally dedicated to converting audio and video signals into digital data that could be transmitted over the Internet. Because of technological convergence, devices are taking on each other's functions (Han, Chung, \& Sohn, 2009). Similarly, 
VolP has expanded the functions it offers. VolP technology offers the following technical features, including audio and video-conferencing, instant messaging, screen sharing, and file sharing. VolP has also expanded its delivery medium from computers to TVs and handheld devices. These technical and nomadic VolP features can be utilized as a cost-effective, one-on-one learning tool to offer individualized e-learning experiences and shorten both physical and virtual "transactional distance" between the instructor and the learner. Therefore, VolP can be an ideal technology to deliver global learning experiences that require one-on-one interactions (Vannoy and Chen, 2012).

Although the use of e-learning is becoming an increasingly important learning trend, VolP systems are not a popular choice among online learners. Rather, online asynchronous or self-paced elearning systems (e.g. WebCT, Moodle, podcast, Edmodo) are thriving because they empower learners to learn from anywhere and at anytime. In addition, although there are more than 120 million subscribers, the VoIP market is highly fragmented (Networkworld Asia, 2011), and VolP providers have not focused on developing e-learning features for the educational sector. A 2012 elearning outlook study shows that many e-learning systems have underperformed because online learners receive little guidance and encouragement towards adopting the systems (e-learning, 2002). VoIP providers must focus on removing cognitive barriers and tailoring their systems to build student user satisfaction. Once the barriers to VoIP as a learning tool from the students' perspective are addressed, VolP systems can become promising tools in education that can enhance students' motivation and communication skills in the global education environment.

Learners are proactive actors and customers in an online learning class (Triki \& Ouerghi, 2007; Ruiz, Sanz, \& Tronch, 2008). Their disposition to accept or reject adopting VolP technology is an important prerequisite to its success in global learning applications. This paper offers an empirical insight into e-learning effectiveness via Skype to increase user satisfaction, individual learning performance, and the continuance intention of using VolP systems in the global learning context. To achieve this goal, we analyzed the potential impact of system success factors including information and system quality, and control belief factor, that is, the perceived behavior control on user satisfaction, individual performance and the intention to reuse. A research model is proposed to integrate seven constructs of IS success model and planned behavior theory. An experiment was conducted as the research method to collect data from 65 American subjects participating in an intercultural communication class. Partial Least Square method was used to analyze the collected data and to test the proposed hypotheses. Findings are reported and discussed with regard to their academic and practical implications. Future research direction and limitations are further discussed to conclude this study.

\section{Theoretical Development}

An information system's success involves at least two important attributes: information and system quality (DeLone \& McLean, 1992). The successful use of VolP technology as a global learning tool should consider these qualities because they are inseparable in the design of an elearning system (Kim et al., 2012). A reliable VolP technology does not guarantee the success of a cross-cultural learning class involving users having language barriers, with different cultural backgrounds, located in different countries, or possessing different personal beliefs. These nontechnical issues are closely related to information quality and control belief. Although it may seem 
obvious that both information and system qualities, as well as personal belief have to be considered when designing a VolP-enabled global learning class, it remains unclear which factor is more important from a user perspective. Limited evidence is available to help us understand which of the three non-technical factors is more conducive to increased usage and user satisfaction that could enhance individual learning performance and the intention to continue using VolP technology as a global learning tool. The following will examine literature related to the logical relationships among these constructs in the context of user satisfaction and VolP adoption.

\section{The Influence of Information Quality on the Satisfied Use of VolP Applications as a Global Learning Tool}

The learning outcome of a global learning program is to help students acquire intercultural communication competence to resolve intercultural misconceptions (Alagic, Rimmington, \& Orel, 2009). Intercultural communication competence can be assessed with learners' skills and knowledge of managing communication in culturally and linguistically diverse context (Beamer, 1998; Henderson, 2005). Therefore, how information is presented can be much more important than system quality to a user. To become the global learning system of choice, VolP providers must concentrate on presentation because VolP technology is just one of many methods available to global learning programs. As e-learning systems become commoditized, high-quality content is the most-important factor to differentiate one e-learning system from another (Boehle, 2005).

Information quality is the measure of information system outputs, including information accuracy, timeliness, relevance, aggregation, and format (Ahituv, 1980). As an alternative to face to face (F2F) meetings, VolP is a media with high information richness because it can enhance information exchangers' understanding within a specific time interval (Daft \& Lengel, 1986). VolP providers are incorporating new media that can further increase the degree of media richness. High rich media should contain four attributes: (1) immediate feedback, (2) the number of cues and channels available, (3) language variety, and (4) information recipient focus (Daft and Lengel, 1984). VolP can be used as an audio- or a video-conferencing tool that can give users timely feedback during the conversation. Body language varies greatly with cultures. A VolP-enabled meeting can help capture body movement of participants and allow participants to clarify any misunderstanding via external links to additional resources such as instant messaging, online translation, website links. These features can help enhance the information accuracy and relevance. Furthermore, screen and document sharing among participants in a VolP-enabled classroom can help users aggregate and present information in different formats. If properly used, VolP technology can achieve task closure and support communication among geographically dispersed teammates as effective as the traditional F2F meeting (Tan, Tan, \& Teo, 2012). Therefore, VolP has the potential of delivering an effective global e-learning program because it contains all of the information quality attributes.

H1: Information quality has a positive influence on user satisfaction with the use of VolP in acquiring intercultural communication competence.

H2: Information quality has a positive influence on the frequency of using VoIP in acquiring intercultural communication competence. 
The Influence of System Quality on the Satisfied Use of VolP Applications as a Global Learning Tool

System quality is an overall representation of the entire system (Bharati, 2003), as well as a measure of all engineering-oriented performance attributes (DeLone and McLean, 2004). System quality has a direct effect on user satisfaction with systems (Wixom and Todd, 2005). Therefore, improving system quality is essential to the success of using VoIP to deliver a global learning class because poor system quality can delay the transmission of sound and images, thereby causing breakdowns during the conversation. VolP requires users to have at least a webcam and a speaker in order to see and talk to each other. High-end webcams and speakers can deliver more vivid images and clearer sound than low-end webcams and speakers. Users are more likely to be satisfied with high quality systems than low ones because they can better capture multiple social cues (e.g. gesture, voice, tone and facial expressions) (Coyle et al., 2001). Understanding linguistic and cultural differences requires some critical thinking and analytical efforts (Rabasso \& Rabasso, 2011). Media with language variety has a higher performance requirement than media with a low variety for analytical tasks (Liim \& Benbasat, 2000). Quality VoIP seamlessly integrating with other technologies (e.g. social media, automatic translation software, instant messaging and screen sharing can help cope with language variety. High system quality can satisfy users with the technology and motivate them to use the technology to complete e-learning tasks (Kim et al., 2012). Thus, the higher system quality that VoIP has, the more satisfied and motivated users are to use the technology in acquiring intercultural communication competence.

H3: System quality has a positive influence on user satisfaction with the use of VolP in acquiring intercultural communication competence.

H4: System quality has a positive influence on the frequency of using VolP in acquiring intercultural communication competence.

The Influence of Use and Perceived Behavioral Control on the Level of Satisfaction with VoIP Applications as a Global Learning Tool

System use has been one of prominent factors accounting for user satisfaction (DeLone and McLean, 1992; Holsapple \& Lee-Post, 2006), thereby increasing individual performance (Hou, 2012). The more frequently used, the more comfortable and satisfied users would be with using an information system (Wang et al. 2008). The basic skills and knowledge required to operate VolP technology include hardware, such as webcam and headphone, and software, such as system and VoIP software. Effective use of VoIP technology to acquire intercultural communication competence requires that users overcome a learning curve. Successfully overcoming the learning curve can lead to the smooth transfer of application-level knowledge and performance enhancement (Kim, Krishnan, \& Argote, 2012). Therefore, the more frequently used, the more comfortable and satisfied users will be with using VolP applications as a global learning tool. 
H5: The more frequent of use with VolP technology, the higher level of user satisfaction with the use of VolP in acquiring intercultural communication competence.

Perceived behavioral control is a user's perception about how easy or difficult it is to perform a behavior (Ajzen, 1991). Under different situations, a user may express different degrees of perceived behavioral control. Perceived behavioral control, similar to perceived self-efficacy, is a significant determinant of various cross-cultural behaviors, such as ethical judgment (Cherry, 2006) and green purchasing behavior (Chan \& Lau, 2002). A cross-cultural study shows that medical professionals in the USA and Ethiopia are more willingly to share knowledge with each other via videoconference-based training support, such as access to experts, sharing experiences, and sense of community (Negash, 2010). These training supports have the potential of increasing learners' perceived self-efficacy. Increasing users' perceived behavioral control with using VolP technology to acquire intercultural communication competence has the potential of satisfying and helping learners cope with linguistic and cultural differences.

H6: Perceived behavioral control has a positive influence on the level of user satisfaction with VolP in acquiring intercultural communication competence.

The Influence of User Satisfaction on Individual Performance in and Loyalty to the Use of VolP Applications as a Global Learning Tool

Users are satisfied with a system if they reach a positive summary psychological state resulting from the consumption experience (Oliver, 1981). However, satisfaction with a system alone can no longer guarantee users' loyalty to the adopted system. The high satisfaction but low loyalty phenomenon is becoming a more common theme in the e-learning market because users are constantly looking for alternative systems that are more cost effective than the adopted system. Therefore, it is important to examine not only user satisfaction but also loyalty cultivation when evaluating the success of e-learning systems.

Satisfaction is a short-term behavior exhibited by users when they are satisfied with a service or product (Bearden \& Teel, 1983; Bolton, 1998). VolP can bring users numerous benefits, such as synchronic collaboration (Dillenbourg et al., 1995); one-on-one interaction (Kearsely, 2000); mutual support for collaborative work (Salter, 2000); intellectual development (MacKnight, 2000); and improving critical thinking skills (Muilenburg \& Berge, 2000). VolP technology has a high degree of fit for cross-cultural communication training (Vannoy \& Chen, 2012). When applying VolP to help users acquire intercultural communication competence, its benefits have the potential of increasing user satisfaction.

H7: User satisfaction with the use of VolP has a positive influence on increasing individual performance in acquiring intercultural communication competence.

Satisfaction can only explain part of loyalty because satisfaction includes the other three elements: value reception, re-purchasing, and customer recommendation to third parties (Zeithaml et al., 1996). The absence of these three elements may explain the prevalence of low loyalty even though users are satisfied with their current e-learning systems. The challenge of differentiating 
between true and spurious loyalty could be another missing piece of this social phenomenon (Shankar et al., 2003). Spurious loyalty is when users repurchase the same product while constantly looking for alternatives in the market (Shankar et al., 2003). This non-true loyalty can appear in the process of adopting VoIP as a global learning tool since the market is so fragmented that many other cost-effective alternatives are readily available for users to adopt. To achieve true loyalty behavior, VolP service providers need to concentrate on building long-term behavior; that is, the intention of users to continue using VolP to acquire intercultural communication competence even though they may experience some problems in service performance (Reichheld, 1993).

H8: Individual performance has a positive influence on increasing the intention of users to continuously use VolP to acquire intercultural communication competence.

Although VolP is considered a natural product to help learners acquire intercultural communication competence, information quality, system quality, and perceived behavioral control are potential barriers to learners' satisfied usage experience. Our literature review indicates that improving these three factors has the potential for increasing both usage frequency and user satisfaction. Consequently, user satisfaction can lead to increased individual performance and the user's intention to reuse Skype as a global learning tool. Figure 1 is our research model showing the relationships among these constructs.

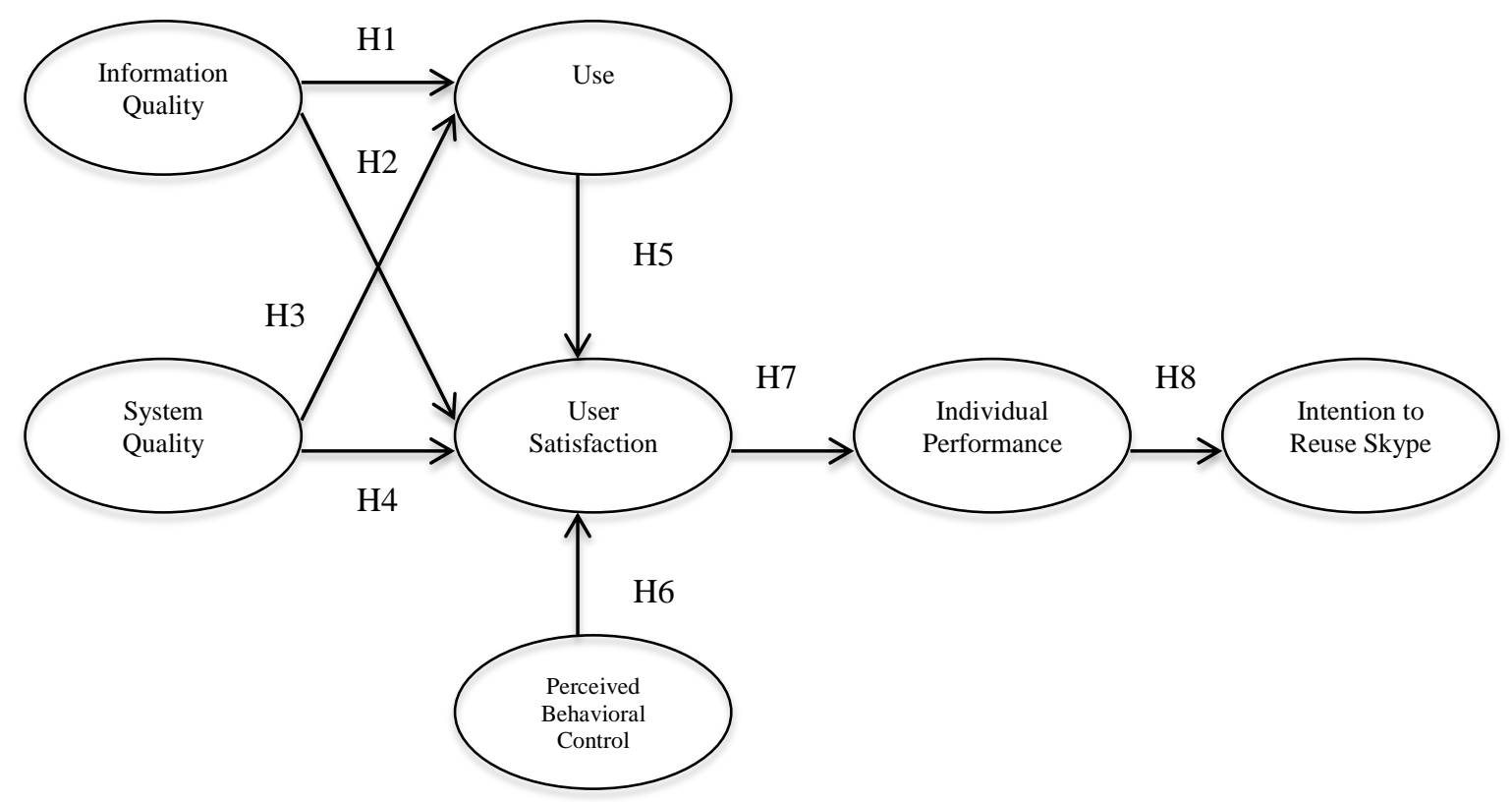

Figure 1. Theoretical Model 


\section{Research Methodology}

Three one-hour sessions of a global learning class were conducted for 66 American and 32 Taiwanese college students to increase their intercultural communication competence. The primary learning goal of these classes was to help all participants increase their understanding of linguistic and cultural difference between the USA and Taiwan. Skype is the VoIP technology chosen to facilitate the cross-cultural communication process. The researchers used Google Doc. to create a document with a broad list of topics linked by a Table of Contents. The purpose of these suggested topics was to give the students certain communication topics so that their discussion would have substance and some measure of structure. Since this is an open document, all students were given one week to add questions and answers under each topic. The entire document with inputs from all students was saved as a PDF file and made available to students as a reference during the global learning classes. This complete document has four chapters: (1) personal experience, (2) personal preference, (3) personal opinions, and (4) personal comparisons. Chapter 1 topics include places, people, culture, food, and hobbies. Chapter 2 topics range from cars, vacation, gifts, indoor activities, to outdoor activities. Chapter 3 topics include chores, beauty, decisions, and zoos. Chapter 4 topics range from jobs, travel, language, news, to food. All participants could freely access this compiled document to assist in their intercultural communication experience during the global learning classes. Figure 2 shows a completed question related to Chapter 1: Culture.

\section{Chapter 1: Culture}

Question: What is one thing that you would change about your culture if you could?

Answer: Don't get me wrong I don't feel that I have it all that bad, but if there was one thing that I could change I would hope that society doesn't lose hold of the personal side of business/general interaction. With the ever increasing rate of technological development I feel like a lot of people rely heavily on new technology. As a result I feel we often fail to embrace the fact that people, both individuals and groups, can do amazing things if simply work together.

\section{Warm-Up Questions:}

- What is a very unique aspect of your culture?

- What other culture do you find very interesting?

- Does technology play a large role in your everyday life?

- Has your culture changed a great deal recently?

Figure 2. Sample Questions

In addition to creating discussion topics, students received a short instructional session on the use of Skype before the global learning classes were conducted. In the beginning of each class, students received the following instructions to complete each session: 
Step 1: Log into Skype with your assigned username and password;

Step 2: Add the corresponding student's Skype username as a new contact;

Step 3: Wait for the student to accept your invitation;

Step 4: Start discussing with each other according to the topics file;

Step 5: Wrap up your discussion;

Step 6: Log out of Skype.

Since we recruited unequal number of American and Taiwanese students, we controlled the matching process so that an American student would be able to communicate with two different Taiwanese students over the three-week period. A graduate assistant or instructor monitored each session in a computer lab during their communications, and were available to resolve technical issues encountered by students. Skype was adopted for this study because of its popularity and installed on all computers in the computer lab. Each student was equipped with a webcam and a headphone and was free to use all cost-free PC-to-PC Skype applications, including video conferencing, text messaging, screen sharing, and document sharing.

\section{Survey}

At the end of three class sessions, American students completed a questionnaire related to the global learning experience. Linguistic and cultural challenges were present during the entire communication because Taiwanese students were struggled with using English to communicate and American students were not familiar with Taiwanese cultures and strong accents. Information quality, system quality, system use, user satisfaction, and individual performance items were adapted from DeLone and McLean (1992). Perceived behavioral control items were adopted from Ajzen (1991). The intention of continuously using VolP to acquire intercultural communication competence was adapted from Bhattacherjee (2001). All questionnaire items were measured on Likert-type (1) = strongly disagree, $(3)$ = neutral, and (5) = strongly agree scales.

\section{Data Analysis}

The Kaiser-Meyer-Olkin Measure of Sampling Adequacy (KMO) and Bartlett's statistical tests were first performed to assess whether the measurement items would yield distinct factors. Table 1 summarizes the results of these two tests for all seven constructs. All KMO values are equal to or higher than the minimum acceptable threshold of 0.50. All Bartlett's Sphere values are significant, indicating that the correlation matrix is not an identify matrix. These positive test results warrant the Structured Equation Modeling (SEM) test.

SmartPLS (Partial Least Squares) was adopted to perform SEM test and analyze the hypothesized relationships among these seven constructs. PLS has minimal restrictions on sample size and residual distribution (Chin et al. 2003). To cope with our limited sample size, the bootstrap resampling method (500 re-samples) was chosen to run the SEM test and assess the measurement and structural models. 
Table 1. Factor Analysis

\begin{tabular}{|l|c|c|}
\hline Factors & KMO Test & Bartlett's Sphere \\
\hline Information Quality (IQ) & $0.851>0.50$ & $\mathrm{p}=0.000<0.01$ \\
\hline System Quality (SQ) & $0.500>0.50$ & $\mathrm{p}=0.000<0.01$ \\
\hline System Use (USE) & $0.702>0.50$ & $\mathrm{p}=0.000<0.01$ \\
\hline User Satisfaction (SAT) & $0.822>0.50$ & $\mathrm{p}=0.000<0.01$ \\
\hline Individual Performance (IP) & $0.732>0.50$ & $\mathrm{p}=0.000<0.01$ \\
\hline Intention to Reuse (ITR) & $0.714>0.50$ & $\mathrm{p}=0.000<0.01$ \\
\hline Perceived Behavioral Control (PBC) & $0.864>0.50$ & $\mathrm{p}=0.000<0.01$ \\
\hline
\end{tabular}

\section{Measurement Model}

Our research instrument was further assessed with Cronbach's alpha, composite reliability, convergent, and discriminant tests. Table 2 shows that Cronbach's alpha values show that the internal consistency of all items used to measure each construct exceeded the generally accepted minimum threshold of 0.70 (Cronbach, 1951). This indicates that all items used to measure each construct carry the same weight (George \& Mallery, 2003). Composite reliability values also exceeded the threshold value of 0.70 (Fornell \& Larcker, 1981; Nunnally 1978), indicating that the actual loadings to construct the factor score have a high internal consistency (Chin, 1998; Chin, Marcolin, \& Newsted, 2003).

Table 2. Construct and Composite Reliability Test Results

\begin{tabular}{|l|c|c|}
\hline Constructs & Composite Reliability & Cronbach's Alpha \\
\hline Information Quality (IQ) & 0.9585 & 0.9424 \\
\hline System Quality (SQ) & 0.9324 & 0.8551 \\
\hline System Use (USE) & 0.9655 & 0.9285 \\
\hline User Satisfaction (SAT) & 0.9393 & 0.9137 \\
\hline Individual Performance (IP) & 0.9215 & 0.8725 \\
\hline Intention to Reuse (ITR) & 0.9386 & 0.9018 \\
\hline Perceived Behavioral Control (PBC) & 0.9415 & 0.9069 \\
\hline
\end{tabular}

Convergent and discriminant validity are two important dimensions of construct validity. Table 3 provides the correlation matrix with the square roots of the Average Variance Extracted (AVE) for each construct reported on the diagonal. Convergent and discriminant validity can be verified when the square root of the construct's AVE is larger than the correlations with other constructs, and convergent validity can be further verified when item loadings on hypothesized constructs are greater than 0.50 (Wixom and Watson 2001). As seen in Table 2, the square roots of the constructs' AVEs are larger than their cross-correlations, indicating that the variance explained by each construct is larger than the measurement error variance. Convergent validity was further verified as all items loaded greater than .50 on their associated constructs. 
Table 3. Convergent and Discriminant Validity Test Results

\begin{tabular}{|l|r|r|r|r|r|l|l|}
\hline & \multicolumn{1}{l|}{ IP } & \multicolumn{1}{l|}{ IQ } & \multicolumn{1}{l|}{ ITR } & PBC & SAT & SQ & USE \\
\hline IP & $\mathbf{0 . 8 9 2 6}$ & & & & & & \\
\hline IQ & 0.6150 & $\mathbf{0 . 9 2 3 4}$ & & & & & \\
\hline ITR & 0.7031 & 0.5216 & $\mathbf{0 . 9 1 4 4}$ & & & & \\
\hline PBC & 0.4632 & 0.3990 & 0.3055 & $\mathbf{0 . 9 1 8 2}$ & & & \\
\hline SAT & 0.5259 & 0.5889 & 0.5481 & 0.5293 & $\mathbf{0 . 8 9 1 4}$ & & \\
\hline SQ & 0.4542 & 0.6442 & 0.3390 & 0.5109 & 0.5794 & $\mathbf{0 . 9 3 4 6}$ & \\
\hline USE & 0.2216 & 0.2001 & 0.3147 & 0.1666 & 0.2422 & 0.1857 & $\mathbf{0 . 9 6 6 0}$ \\
\hline
\end{tabular}

\section{Structural Model and Hypothesis Testing}

SEM test was performed to calculate the estimated path coefficients, path significance and R2 values. Table 4 shows the SEM test results, including path coefficients and their respective tstatistics. Figure 3 depicts path coefficients and variance, indicating that four of the eight hypotheses were supported at either $p<.01$ or $p<.05$. As shown in Table 3 and Figure 3 , Hypothesis 1 (H1) was rejected indicating that information quality has no significant effect on the increase of VolP use in acquiring intercultural communication competence. However, $\mathrm{H} 2$ was supported indicating that information quality has statistically significant impact upon user satisfaction. H3 and $\mathrm{H} 4$ were rejected indicating that system quality has no significant impacts on either VolP usage and user satisfaction. H5 was rejected indicating that no statistical support for the direct, positive relationship between usage frequency and user satisfaction.

In contrast, $\mathrm{H} 6$ was supported, indicating that the control belief factor perceived behavior control has a significant positive effect on the increase of user satisfaction. Information quality, system quality, VoIP usage, and user satisfaction are four antecedent constructs for user satisfaction. These four constructs together explain approximately $48 \%$ of variation in user satisfaction $\left(R^{2}=48.2\right)$. A closer look at the explanative power of these four constructs for the variation in user satisfaction. System quality and VoIP usage have marginal effect. Perceived behavioral control has the strongest effect on user satisfaction, followed by information quality.

$\mathrm{H} 7$ and $\mathrm{H} 8$ were supported indicating that satisfaction has a positive effect on individual performance, thereby increasing the intention of users to reuse VolP in acquiring intercultural communication competence. The structural path from individual performance to the intention to reuse VolP is the strongest path in our model and can explain almost $50 \%$ of the variance in the ITR $\left(R^{2}=49.4\right)$. In addition, results show that user satisfaction has a strong positive effect on the increase of individual performance in intercultural communication competence $\left(R^{2}=28.6\right)$. 
Table 4. Structural Equation Modeling Test Results

\begin{tabular}{|c|c|c|}
\hline Hypothesized Paths & Path Coefficients & T-statistics \\
\hline $\mathrm{H} 1: \mathrm{IQ} \rightarrow$ USE & 0.861 & 0.788 \\
\hline H2: IQ $\rightarrow$ SAT* $^{*}$ & 2.267 & 2.228 \\
\hline H3: SQ $\rightarrow$ USE & 0.649 & 0.596 \\
\hline $\mathrm{H} 4: \mathrm{SQ} \rightarrow \mathrm{SAT}$ & 1.142 & 1.114 \\
\hline H5: USE $\rightarrow$ SAT & 0.986 & 1.040 \\
\hline H6: PBC $\rightarrow$ SAT $^{* *}$ & 2.349 & 2.493 \\
\hline H7: SAT $\rightarrow$ IP** & 4.897 & 5.084 \\
\hline H8: IP $\rightarrow$ ITR** & 10.077 & 10.459 \\
\hline
\end{tabular}

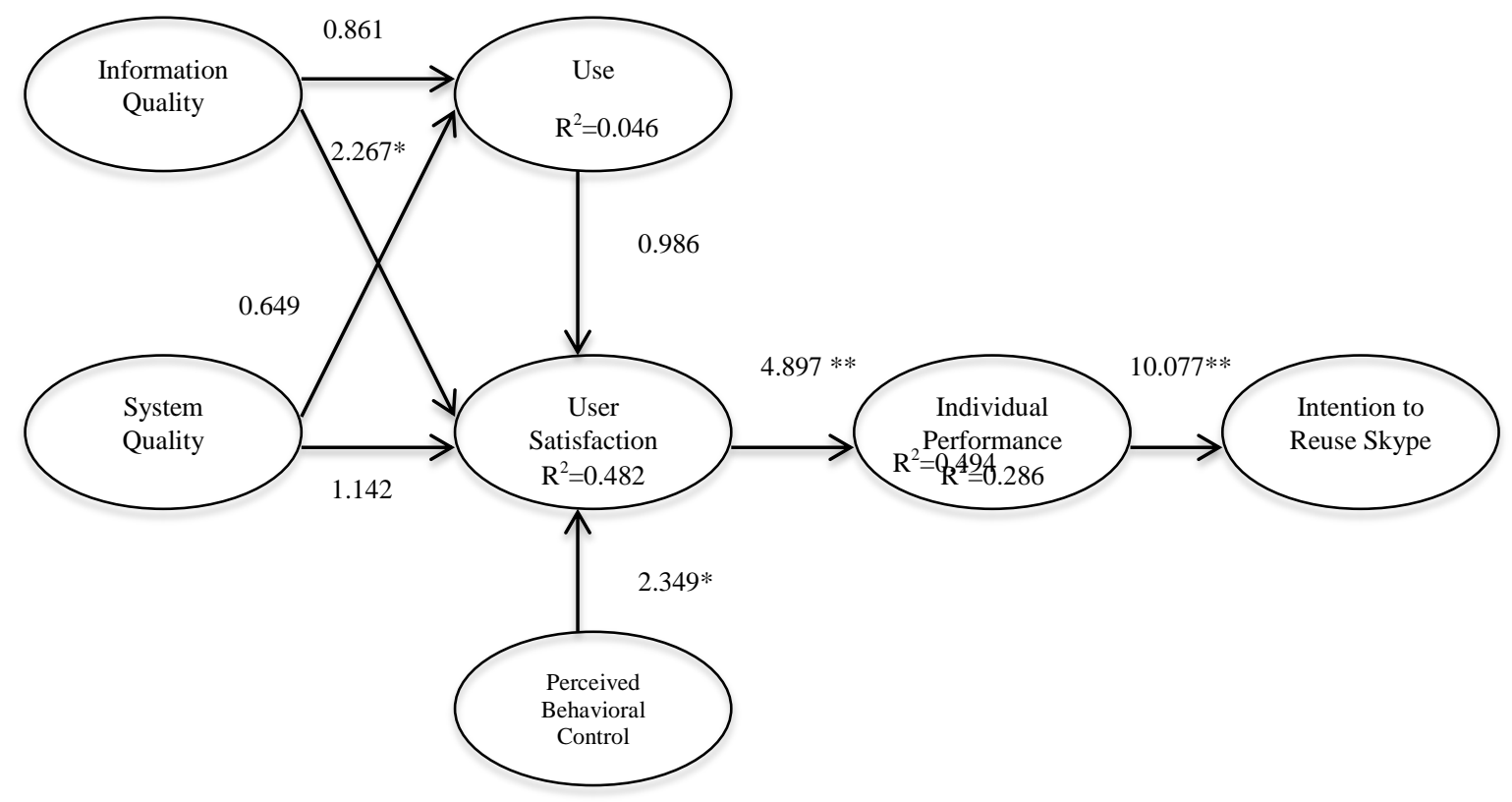

Figure 3. Path Analysis Results

\section{Discussion and Implications}

These research findings show some interesting insights into the relative importance of information system success and control belief factors for the increase of user satisfaction with the use and reuse of VolP to acquire intercultural communication competence. Firstly, perceived behavioral control belief plays an important role for the increase of user satisfaction with the use of VolP for intercultural communication learning. The competence of appreciating another culture consists many essential elements, such as sensitivity (Chen \& Starosta, 2000), dispositions (Gudykunst, Wiseman, \& Hammer, 1977), respect, open-mindedness, empathy, and curiosity (Deardorff, 2006). 
In addition, perceived technical control of verbal and visual aids are essential to the acquisition of intercultural communication competence $(\mathrm{Yu}, 2012)$. All these technical and intercultural communication qualities are essential to the development of perceived behavioral control. Learners can express learning dissatisfaction if they are equipped with VolP technology without first developing the perceived self-control. Lack of perceived control in these competencies has made some American students form negative beliefs. For instance, one student said, "She didn't want to talk to me very much." Another student said, "I don't know another language." Some other students have the belief "I am better at communicating face to face." Students who have the low degree of perceived behavioral control are more likely to have dissatisfied global learning experiences via VolP technology.

On the contrary, learners having a high degree of perceived behavioral control of technical and intercultural communication competencies are more likely to enjoy the VolP-enabled global learning program. According to the Theory of Planned Behavior (TPB), users are more likely to achieve their desired outcomes if the skills, resources, and opportunities considered important by users are available to them (Davis, Bagozzi, \& Warshaw, 1989). Perceived technical and intercultural communication competencies are "user-situational factors" that have strong correlation with the measure of overall satisfaction (Alavi \& Joachimsthaler, 1992). Learners who exhibit high perceived behavior control of their technical (e.g. operating webcam, headphone and VolP software) and intercultural communication (e.g. respect, curiosity, empathy) competencies have brought satisfactory experiences to some of the students participating in this study. Some positive comments expressed by students with high belief in perceived behavior control are:

"It was cool to talk to someone from another country."

"It was funny seeing us both struggle to understand each other and it made us connect in a more friendly way."

"I was able to interact with an individual thousands of miles away, and carry a conversation and see their reactions."

"I liked discovering what he did in his spare time with his friends, because what people in Taiwan do in their spare time might be different from what we do in our spare time."

"It was fun and nice seeing what other cultures are like."

"It was comfortable and laid back. It was a good atmosphere to be able to talk to her."

"I realized that the language barrier is not that difficult and people from all over the world have similar interests."

"Skype showed me a better and different way to communicate."

"The world felt very small because it was very simple. That is encouraging."

These comments corroborate the finding that perceived behavioral control belief is a prerequisite to users' satisfaction with the use of VolP to acquire intercultural communication competence.

Secondly, not all information systems success factors can increase learners' satisfaction with the use of VolP to acquire intercultural communication competence. Our findings show that information quality rather than system quality can help increase user satisfaction. Many intercultural communication studies experiment with the use of various creative methods to increase information quality in the intercultural communication training and learners' satisfaction. Some of these methods are comedy film, games, role-playing, simulation, conflict-resolution 
exercise, problem solving activities, and virtual interactions (Bennett, 1993; Byram, 1997; Fennes \& Hapgood, 1997; Kayes, 2002; Mintzberg \& Goslin, 2002). After using VolP to interact with Taiwanese counterparts, some American students expressed their satisfaction with the use of VolP to acquire intercultural communication competences as follows:

"I learned their hobbies and what their interests were."

"They don't like dogs in Taiwan. Music has lots of American influences."

"They don't like sports and they like to relax."

"The language barrier is the most difficult aspect to overcome."

"They were very nice and interested about our lifestyle."

"He watched Wolverine and was very surprised that I had seen it too. His English was very good, but he thought it wasn't."

"She likes Channing Tatum. She likes to watch soccer. And she dances."

"He enjoys movies. His favorite is A Beautiful Mind. He watches the MLB and the NBA. His favorite teams are the Tampa Bay Rays and the Portland Trail Blazes. He also enjoys mountain biking. He has a lot of work this year in this sophomore year of college. He has a presentation due tomorrow. He has also been to China and had a good time there."

In contrast, many students have taken the system quality for granted and expressed the easiness of using VolP for global cultural learning. When asked "How many more sessions would you need till the person you worked with was able to easily hold a conversation in English?" About $47 \%$ of participants chose the answer "none, they can hold a conversation now." When asked "Describe the most negative aspect of the experience you just had?" most learners said, "none come to mind or nothing." Only a few students complained about background noise in the computer lab and minor technical issues associated with a few webcams and headphones. Some of these students' comments further confirm the necessity of system quality in holding a VolP-enabled learning session:

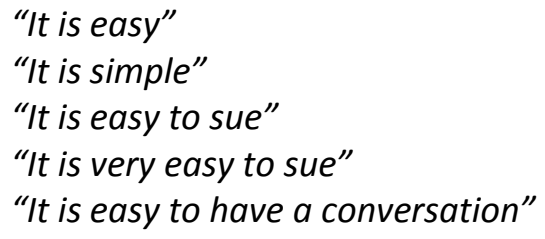

These findings are similar to the result of Schaupp et al. (2009) that system quality could have positive, but insignificant effect on users satisfaction with e-commerce websites. When users have other concerns (e.g. information quality and service quality), they often choose not to complicate system quality issues while using systems to achieve their desired outcomes (e.g. online shopping) (Yang, 2007). This explains the minimal influence of system quality and system use on user satisfaction because of their marginal contribution.

Thirdly, learners who are satisfied with the VolP-enabled global learning experiences tend to show better learning outcomes. This finding is consistent with that of previous technology-enabled learning studies that students who have meaningful experiences of system interaction can have higher perceived learning outcomes and satisfaction (Alshare \& Lane, 2011). 
Positive comments about this experience include:

"Skype is a useful way to get to know another culture because it makes things more personal."

"Its as if you're speaking to them in person."

"It allows you to connect with people that you would never meet otherwise."

"Skype enables you to have an interaction you might not have had."

"You can ask them questions and answer questions face to face."

"It serves as a way to see nonverbal cues that can not be visible by a simple phone call."

"I feel like it gives you a sense of the personality of the person."

"You can talk to other people around the world and learn some things about them. I think it is useful because you can also put a name and a voice with a face."

Lastly, users who experienced good learning outcomes are more likely to reuse VolP technology to acquire intercultural communication competence. Satisfaction is one of key factors influencing the intention of users to reuse their adopted information systems (Kettinger, Park, \& Smith, 2009). Some of the reuse intention could be reflected in the following comments:

"It was interesting trying to talk to a new person using the technology."

"I made new Facebook friends."

"Learning about a friend in Taiwan"

"Talking to someone new and learning about other people"

"I overcame my fear a little bit."

"I really enjoyed the opportunity of getting to meet someone from another culture and learn what kind of similar interests we hare."

I go to laugh with them and learn about their lives and the experiences they have had and hope to have."

"Connecting with someone of the other side of the world. It's great!"

"Yes, I am going to use Skype again."

All these findings affirm that VolP technology can be an effective tool to help learners achieve a satisfied global learning experience. Special emphasis should be placed on information quality instead of system quality because VolP technology is widely available now and the learning curve is no longer steep for most college students. In addition, learners' perceived behavioral control belief is equally, if not more important than information quality. When choosing right media to produce social conditions conducive to the effective global collaboration, intercultural communication learners need to recognize cultural differences and have the ability to use a common language (McNair \& Paretti, 2010). An instructor should emphasize linguistic and cultural differences between information senders and receivers before conducting an intercultural communication learning class.

Allowing learners extra time to develop VolP skills and for studying learning materials and students' backgrounds can also help increase the perceived behavioral control. The instructor should encourage students to develop skills with using VolP before beginning intercultural communication in order to increase learners' satisfaction with the use of VolP. To beat competing systems in the battle for user loyalty, VoIP service providers should demonstrate students' 
individual learning performance because doing so can directly contribute to the increase of loyalty to the use of this technology for the acquisition of intercultural communication competence. Improved performance or net benefit is the supply side of system use, and will result in the increased demand for system reuse (Kulkarni, Ravindran, \& Freeze, 2006).

Effective use of technology to exchange intercultural information can help learners become less prejudiced and develop more understanding of others' linguistic and cultural differences (Simsek and Nuss, 2010). VolP-enabled global learning can promote the exchange of intercultural communication across borders and, most importantly, learners' intercultural communication competence.

\section{Future Research and Limitations}

Rapid technology innovation continues to accelerate the globalization process (Friedman, 2005). However, it is a myth that advance technology can naturally lead to the accelerated globalization trend. This study proves otherwise by showing that information quality could be much more important than system quality in the globalization process. A study on international sales team performance shows that the primary purpose of increasing technology sophistication is to improve the quality of cross-cultural communication among international sales team members (Ritchie et al., 2011). Information quality is a general construct comprising many attributes such as information accuracy, timeliness, relevance, aggregation, and format (Ahituv, 1985). However, it is unclear which attributes contribute more to the satisfied use of VolP for intercultural communication training. Future research may want to manipulate the control of these attributes and provide more insights on how to more effectively deliver a VolP-enabled global learning class.

The effectiveness of a VolP-enabled global learning program also relies on the belief of learners in their success in overcoming technical, linguistic, and cultural barriers. Removing these barriers can help increase the degree of perceived behavioral control for users participating in global learning sessions. Although this finding sheds lights on the importance of perceived behavioral control, many other control beliefs are also prominent but not examined in this study. Control beliefs that could be important in the technology-enabled learning may include: locus of control (Rotter, 1966), self-efficacy (Bandura, 1977), perceived situational control (Wallston, 1989), and helplessness (Seligman, 1975). Future study may focus on examining the influence of different control beliefs on learners' satisfaction with the use of VolP to enhance their intercultural communication competence.

As VolP technology reaches its maturity, the challenges of increasing user loyalty remain high for its service providers. It is imperative to introduce new features to the current VolP technology in order to increase information quality. During the three-week sessions, some students relied heavily on online translation services (e.g. Google translation) to help understand difficult English words or simple Chinese words spoken by their counterparts in Taiwan. Other students used Social media (e.g. Facebook) to share their backgrounds and common interests. These extra efforts helped learners better understand each other and increased their gratifying experiences. VolP service providers should search for novelty technologies (e.g. smart phone, virtual reality) and integrate them into their current systems. Future study can experiment with the use of a 
combination of different technologies in addition to VolP and assess their combined effect on user satisfaction and the intention of reusing VolP to acquire intercultural communication competence.

Cultural differences (individualism, power distance, uncertainty avoidance, masculinity and longterm orientation) (Hofstede, 2007) have influence on technology adoption behavior (Straub, 1994). These differences should be properly assessed with respect to their potential influence on the findings of this study. For instance, individualists prefer to use the Internet to complete an automobile purchase without consulting with friends and families whereas collectivists always do the opposite (Nayeem, 2012). Collectivists always seek feedback from their peers on electronic discussion boards (Hwang and Francesco, 2010). Thus, technology adoption behaviors cannot hold universally across cultures and their potential influence has to be properly assessed for any new technology (Srite \& Karahanna, 2006). Future research may want to examine the moderating effect of different cultural dimensions on the hypothesized relationships of this study.

Incentives offered to American and Taiwanese students were different. American students were offered extra credit for their participation in this study, whereas Taiwanese students participated in this study on a voluntary basis. The difference in incentive may have contributed to the findings of this study based on only American samples. A 13-hour time difference between Taiwan and the United States may also have affected the attitude toward this study and ultimately the participation rate. When the communications took place, American students were asked to come to a computer lab as early as 8 am and Taiwanese students as late as $9 \mathrm{pm}$. These two hours are not appealing to students of either side. The suboptimal situation may have contributed to the low participation of Taiwanese students when they were not motivated with any incentives. One side effect out of this temporal difference is the process of unequally pairing American and Taiwanese students for one-on-one learning experiences. Generalizing the findings of this study to business professionals warrants special consideration because the findings are based on student samples. Future study may want to overcome these limitations and provide a more complete picture about the use and reuse of VolP for the acquisition of intercultural communication competence.

\section{Conclusion}

As the technology is helping to flatten the world, globalization can be further accelerated with an increasing number of people developing intercultural communication competencies. E-learning is one of many means to help achieve this goal. This study examines VolP as a promising technology to help users acquire intercultural communication skills because of its perceived fit for this purpose. However, low user loyalty is one persistent challenge that VoIP and other e-learning technologies are facing. To help overcome the challenge, this study demonstrates that the increase in user loyalty relies heavily on the improvement of individual performance via VolPenabled intercultural training programs. Information quality and perceived behavioral control are two critical antecedents for learners' satisfaction with the use of VoIP to acquire intercultural communication competence. The increased satisfaction will enhance learning outcomes, thereby developing users' loyalty to VoIP. This study offers the perspectives of information system success and control belief that it is pragmatic and feasible to use and reuse VolP technology as a crosscultural communication tool. 


\section{References}

Ahituv, N. (1980). A systematic approach toward assessing the value of an information system. MIS Quarterly, 4(4), 61-75.

Ajzen, I. (1985). From intentions to actions: A theory of planned behavior, In J. Kuhl and J. Beckmann (Eds.), Action-control: From cognition to behavior (pp. 11-39). Heidelberg: Springer.

Ajzen, I. (1991). The theory of planned behavior. Organizational Behavior and Human Decision Processes, 50(2), 179-211.

Alagic, M., Rimmington, G.M., \& Orel, T. (2009). Third place learning environments: Perspective sharing and perspective taking. International Journal of Advanced Corporate Learning, 2(4), 4-8.

Alavi, M. \& Joachimsthaler, E.A. (1992). Revisiting DSS implementation research: A meta-analysis of the literature and suggestions for researchers. MIS Quarterly, 16(1), 95-116.

Alshare, K.A. \& Lane, P.L. (2011). Predicting student-perceived learning outcomes and satisfaction in ERP courses: An empirical investigation. Communications of the Association for Information Systems, 28(1), 571-584.

Bandura, A. (1977a) Social learning theory. New York: Prentice Hall.

Beamer, L. (1992). Bridging business culture. China Business Review, 25, 54-58.

Bearden, W. O. \& Teel, J. E. (1983). An investigation of personal influences on consumer complaining. Journal of Marketing Research, 20, 21-28.

Bennett, M. J. (1993). Towards ethnorelativism: A developmental model of intercultural sensitivity. In M. R. Paige (Ed.), Education for the intercultural experience (pp. 109-135). Yarmouth, ME: Intercultural Press.

Bharati, P. (2003). People and information matter: Task support satisfaction from the other side. Journal of Computer Information Systems, 43(2), 93-102.

Boehle, S. (2005). The state of the e-learning market. Training, 42(9), 12-18.

Bolton, R. (1998). A dynamic model of the duration of the customer's relationship with a continuous service provider: The role of satisfaction. Marketing Science, 17(1), 45-65.

Byram, M. (1997). Teaching and assessing intercultural communicative competence. Clevedon, United Kingdom: Multilingual Matters.

Chan, R.Y.K. \& Lau, L.B.Y. (2002). Explaining green purchasing behavior: A cross-cultural study on American and Chinese consumers. Journal of International Consumer Marketing, 14(2/3), 940.

Chen, G. M. \& Starosta, W. J. (2000). The development and validation of the intercultural sensitivity scale. Paper presented at the Annual Meeting of National Communication Association, Seattle, WA. Retrieved from ERIC database. 
Cherry, J. (2006). The impact of normative influence and locus of control on ethical judgments and intentions: A cross-cultural comparison. Journal of Business Ethics, 68(20), 113-132.

Chin, W. (1998). Issues and opinion on structural equation modeling. MIS Quarterly, 22(1), 7-16.

Chin, W., Marcolin, B. \& Newsted, P. (2003). A partial least squares latent variable modeling approach for measuring interaction effects: Results from a Monte Carlo simulation study and an electronic mail adoption study. Information Systems Research, 14(2), 189-217.

Coyle, J. R. \& Thorson, E. (2001). The effects of progressive levels of interactivity and vividness in web marketing sites. Journal of Advertising, 30(3), 65-77.

Cronbach, L. J. (1951). Coefficient alpha and the internal structure of tests. Psychometrika, 16, 297-334.

Daft, R.L. \& Lengel, R.H. (1984). Information richness: A new approach to managerial behavior and organizational design. In: L.L. Cummings \& B. M. Staw (Eds.), Research in organizational behavior 6, (pp. 191-233). Homewood, IL: JAI Press.

Davis, F., Bagozzi, R., \& Warshaw, P. (1989). User acceptance of computer technology: A comparison of two theoretical models. Management Science, 35(8), 982-1003.

Deardorff, D. K. (2006). Identification and assessment of intercultural competence as a student outcome of internationalization. Journal of Studies in International Education, 10(3), 241266.

DeLone, W.H. \& McLean, E.R. (1992). Information system success: The quest for dependent variable, Information Systems Research, 3(1), 60-95.

DeLone, W.H. \& McLean, E.R. (2004). Measuring e-commerce Success: Applying the DeLone \& McLean Information Systems Success Model. International Journal of Electronic Commerce, 9(1), 31-47.

Dillenbourg, P., Baker, M., Blaye, A., \& O'Malley, C. (1995) The evolution of research on collaborative learning. In E. Spada \& P. Reiman (Eds.), Learning in humans and machine: Towards an interdisciplinary learning science (pp. 189-211) Oxford: Elsevier.

Fennes, H. \& Hapgood, K. (1997). Intercultural learning in the classroom: Crossing borders. London: Cassell.

Fornell, C. \& Larcker, V.F. (1981). Evaluating structural equation models with unobservable variables and measurement error. Journal of Marketing Research, 18(1), 39-50.

Friedman, T. (2005). The world is flat: A brief history of the twenty-first century. New York: Farrar, Straus and Giroux.

George, D. \& Mallery, P. (2003). SPSS for Windows step by step: A simple guide and reference. 11.0 update $\left(4^{\text {th }}\right.$ ed.). Boston, MA: Allyn \& Bacon.

Gudykunst, W. B., Wiseman, R. L., \& Hammer, M. R. (1977). Determinants of a sojourner's attitudinal satisfaction: A path model. In B. D. Ruben (Ed.), Communication yearbook (pp. 415-425). New Brunswick, NJ: Transaction.

Han, J.K., Chung, S.W., \& Sohn, Y.S. (2009). Technology convergence: When do consumers prefer converged products to dedicated products? Journal of Marketing, 73(4), 97-108. 
Henderson, J.K. (2005). Language diversity in international management teams. International Studies of Management and Organization, 35, 66-82.

Hofstede, G. (2001). Culture's consequences: Comparing values, behaviors, institutions, and organizations across nations (2nd ed.). Thousand Oaks, CA: Sage.

Holsapple, C.W. \& Lee-Post, A. (2006). Defining, assessing, and promoting e-learning success: An information systems perspective. Decision Sciences Journal of Innovative Education, 4(1), 6785.

Hou, C. (2012). Examining the effect of user satisfaction on system usage and individual performance with business intelligent systems: An empirical study of Taiwan's electronics industry. International Journal of Information Management, 32(6), 560-573.

Hwang, A. \& Francesco, A.M. (2010). The influence of individualism-collectivism and power distance on use of feedback channels and consequences for learning. Academy of Management Learning \& Education, 9(2), 243-257.

Kayes, D. C. (2002). Experiential learning and its critics: Preserving the role of experience in management learning and education. Academy of Management Learning and Education, 1(2), 137-149.

Kearsley, G. (2000). Learning and teaching in cyberspace. Retrieved on 5 September 2000 from http://home.sprynet.com $\sim$ gkearsley/chapts.htm.

Kettinger, W.J., Park, S., \& Smith, J. (2009). Understanding the consequences of information systems service quality on IS service reuse. Information \& Management, 46(6), 335-341.

Kim, Y., Krishnan, R., \& Argote, L. (2012). The learning curve of knowledge workers in a professional call center. Information Systems Research, 23(3), 887-902.

Kim, K., Trimi, S., Park, H., \& Rhee, S. (2012). The impact of CMS quality on the outcomes of elearning systems in higher education: An empirical study. Decision Sciences Journal of Innovative Education, 10(4), 575-587.

Kulkarni, U.R., Ravindran, S., \& Freeze, R. (2006). A knowledge management success model: Theoretical development and empirical validation. Journal of Management Information Systems, 23(3), 309-347.

Lim, K.H., \& Benbasat, I. (2000). The effect of multimedia on perceived equivocality and perceived usefulness on information systems. MIS Quarterly, 24(3), 449-471.

MacKnight, C. B. (2000). Teaching critical thinking through online discussions. Educause Quarterly, 4, 38-41.

McNair, L.D. \& Paretti, M.C. (201). Activity theory, speech acts, and the "Doctrine of Infelicity": Connecting language and technology in globally networked learning environments. Journal of Business \& Technical Communication, 24(3), 323-357.

Mintzberg, H. \& Gosling, J. (2002). Educating managers beyond borders. Academy of Management Learning and Education, 1(1), 64-76.

Moore, M. G. (1983). The individual adult learner. In M. Tight (Ed.), Adult learning and education (pp. 153-168). London: Croom Helm. 
Muilenberg, L. \& Berge, Z. (2002). A framework for designing question for online learning. Retrieved on 22 August, 2002 from http://www.ssn.flinders.edu.au/innovations/ teacherresources.html

Nayeem, T. (2012). Cultural influences on consumer behavior. International Journal of Business \& Management, $7(21), 78-91$.

Negash, S. (2010). Learning assessment of a videoconference-based training: Lessons from medical training between USA and Ethiopia. Information Technology for Development, 16(3), 212231.

NetworkWorld Asia (Sep/Oct, 2011). VolP market set to generate \$40 billion a year by 2015. NetworkWorld Asia, 8(3), 5.

Nunnally, J. C. (1978). Psychometric theory. New York, NY: McGraw-Hill.

Oliver, R. L. (1981). Measurement and evaluation of satisfaction processes in retail settings. Journal of Retailing, 57(3), 25-48.

Rabasso, C.A. \& Rabasso, J. (2011). Educating responsible transcultural managers for open environments and organizations. International Journal of Employment Studies, 19(2), 33-61.

Reichheld, F. F. (1993). Loyalty-based management. Harvard Business Review, 71(2), 64-73.

Ritchie, W.J., Drew, S.A., Srite, M., Andrews, P., \& Carter, J.E. (2011). Application of a learning management system for knowledge management: Adoption and cross-cultural factors. Knowledge \& Process Management, 18(2), 75-84.

Rotter, J.B. (1966). Generalized expectations for internal versus external control of reinforcement. Psychological Monographs, 80, 1-28.

Ruiz, C., Sanz, S., \& Tronch, J. (2008). Motivators and inhibitors of distance-learning courses adoption: The case of Spanish consumers. In M. Negash, A. Whitman, K. Woszczynski, Y. Hoganson, \& H. Mattord (Eds.), Handbook of distance learning for real-time and asynchronous information technology education (pp. 296-316). Hershey (PA): IGI Global.

Saba, F. \& Shearer, R. L. (1994). Verifying key theoretical concepts in a dynamic model of distance education. The American Journal of Distance Education, 8(1), 36-59.

Salter, G. (2000). Making use of online discussion groups. Journal of the Australian Council for Computers in Education, 15(2), 5-10.

Schaupp, L.C., Belanger, F., \& Fan, W. (2009). Examining the success of websites beyond ecommerce: An extension of the IS success model. The Journal of Computer Information Systems, 49(4), 42-52.

Seilgman, M.E.P. (1975). Helplessness. San Francisco: Freeman.

Shankar, V., Smith, A., \& Rangaswamy, A. (2003). Customer satisfaction and loyalty in online and offline environments. International Journal of Research in Marketing, 20, 153-175.

Simsek, A. \& Nuss, S. (2010). Snapshots of a culture: How do American and Turkish elementary students represent their cultural identities using technology as a means of expression and communication? Contemporary Educational Technology, 1(4), 288-305. 
Straub, D.W. (1994). The effect of culture on IT diffusion: Email and fax in Japan and the U.S., Information Systems Research, 5(1), 23-47.

Srite, M. \& Karahanna, E. (2006). The role of espoused national cultural values in technology acceptance. MIS Quarterly, 30(3), 679-704.

Tan, W., Tan, C., \& Teo, H. (2012) Conveying information effectively in a virtual world: Insights from synthesized task closure and media richness. Journal of the American Society for Information Science \& Technology, 63(6), 1198-1212.

Triki, A. \& Ouerghi, O. (2007). The Tunisian E-learning experience: A focus on the main actors perceptions. In L. Gómez, D. Martí, and I. Candel (Eds.), International Association of Technology, Education and Development Conference Proceedings. Valencia: IATED.

Vannoy, S. A. \& Chen, C.H. (2012). Intercultural communication competence via IP services applications: A modified task-technology fit perspective. Journal of Global Information Technology Management, 15(3), 55-80.

Wallston, K.A. (1989). Assessment of control in health care settings. In A. Steptoe and A. Appels (Eds.) Stress, personal control and health (pp. 85-105). Chicester, England: Wiley.

Wang, W., Hsieh, J.P., Butler, J.E., \& Hsu, S.H. (2008). Innovate with complex information technologies: A theoretical model and empirical examination. The Journal of Computer Information Systems, 49(1), 27-36.

Wedemeyer, C. A. (1981). Learning at the back door: Reflections on non-traditional learning in the lifespan. Madison, WI: University of Wisconsin Press.

Wixom, B.H. \& Todd, P.A. (2005). A theoretical integration of user satisfaction and technology acceptance. Information Systems Research, 16(1), 85-102.

Yang, H. (2007). Assessing the effects of e-quality and e-satisfaction on website loyalty. International Journal of Mathematics and Computer in Simulation, 1(3), 288-294.

$\mathrm{Yu}, \mathrm{H}$. (2012). Intercultural competence in technical communication: A working definition and review of assessment methods. Technical Communication Quarterly, 21(2), 168-186.

Zeithaml, V.A., Berry, L.L., \& Parasuraman, A. (1996). The behavioural consequences of service quality. Journal of Marketing, 60(2), 31-46.

Correspondence: Charlie C. Chen, Associate Professor, Department of Computer Information Systems, Walker College of Business, Appalachian State University, Boone, North Carolina, United States. 